\title{
Mental health care and the big IT
}

\section{A personal view}

\author{
Gyles R. Glover
}

\begin{abstract}
When I was af school the blg II everyone falked about, some explored ovidly and others shunned nervously was sox. In poychiatry todoy, as in so many other fields IT is information technology. This article is a polemic. I belleve II (the now sort) is indispensable for modem mental health care. In the Brttish National Health Service we have a window of opportunily to get $I \pi$ right and $I$ clinicians fall to act decisively and quickly, there is a risk that the chance will be lost.
\end{abstract}

\section{Why do mental health services need IT?}

Information technology (IT) is everywhere today; everywhere that is except in most mental health services. This article is a polemic statement of the view that this is a problem. I believe IT is indispensable for modern mental health care. In the British National Health Service (NHS) we have a window of opportunity to get IT right and if clinicians fail to act decisively and quickly, there is a risk that the chance will be lost.

To be indispensable, there must be key clinical benefits. The most important is communication. Modern community-based services are increasingly geographically dispersed - a necessary corollary of being closer to patients' homes. Many patients get care in several contexts - a day hospital, community psychiatric nurse visits, out-patients. In general the more chronically disabled the patient, the more elements will be involved. Frequently these are each based in different places. The mental health Trust for Western Surrey operates from seventeen separate sites. In ideal circumstances coordination is ensured by staff from the various places meeting at care reviews. Realistically, given the large numbers of patients recelving this type of mix and match care, this is not always practical. Conventional case notes will not help since evidently no one folder can be in several places all the time. The risk is that each care setting will develop its own notes, its own view of the patient and its own care plan.

One way to counter this inherent tendency to fragmentation is to use computer-based care plans, accessible to staff at all care settings, as a central communication vehicle. Such systems are particularly helpful to staff on-call for emergencies. Peter Rohde (1992) proposed this approach in principle in the late 1980 s. A number of systems offering this capability are now commercially available.

Beyond communication, a number of other clinical uses for IT systems have been described. These range from aides-mémoire to ensure patients do not fall unnoticed out of care, to expert systems to streamline neuroleptic dosage regimes (Taylor, 1992). Computers may be useful in all these ways. But as a means to provide wide and immediate availability of the current consensus about each patient's care, crucial in countering the otherwise inevitable tendency for dispersed services to fragment, there is no realistic substitute.

There are two other reasons why cliniclans need IT. The first is the battle for resources. Today this is a fight for all divisions in all specialities - a situation unlikely to change. Success in this battle usually goes to the person with the best information. For years surgeons considered waiting lists their most bankable asset. The parallel for mental health services surely must be to demonstrate that the number of patients with substantial, quantifiable care needs constitutes a caseload in excess of the resources available. This case can only be made with credible numbers.

The second, indirect use is in analysing where the money goes and to what effect. While there may be insufficient resources for mental health care in some places, the problem of poorly directed resources is a much wider one. The efficlency of current resource deployment and the extent to which capital and revenue could be freed to provide more appropriate care are issues few services have the information to assess. While this deficiency persists the lingering suspicion that cash allocated to mental health care is not used effectively will impede the fight for more.

\section{Why do we have an opportunity?}

We have an opportunity quite simply because the Department of Health (DoH), which allocates 
funds to the NHS and its mental health services, oversees its operation and determines its priorities, has got the message. For three years, successive policy documents have emphasised the key role of IT in supporting and coordinating clinical mental health care (Secretary of State, 1992; Department of Health, 1994). There is also an urgent need for information to develop more effective descriptions of mental health care to permit more sophisticated management and purchasing. The clinical and management information needs cannot be separated since both require information systems richer in clinical detail than those designed for Korner returns.

Two specific actions last year underscore the DoH commitment. One is the development of a new Minimum Data Set (MDS) for purchaser/ provider agreements about the amount of care being provided and for national statistics. The current framework was designed nearly fifteen years ago when the methods of mental health care outside institutions were less developed. Inevitably it reflects a pattern of care which focuses largely on hospital admission and visits to doctors' in-patients. Little detail of the patterns of multidisciplinary community based care emerges.

The new data set centres on repeated recordings of the patients' clinical state (diagnosis and Health of the Nation Outcome Scales (HoNOS) scores), the care they have had and the current care plan. Care delivered and planned will only be required in outline form for the mandatory returns, but the configuration of the data set is intended to act as the skeleton of a current clinical summary which will be of central value to all those involved in the patients' care. Pllot studies of the data set are under way in nine provider units each of which, it is hoped, will eventually act as a local demonstrator site. An information leaflet including details of the pilot sites was published last August and copies are available from the DoH (Information Management Group, 1995).

The other, and most explicit statement of the urgency the DoH places on IT for mental health care, is the new set of Priorities and Planning Guidance for the NHS (NHS Executtve, 1995). This is the statement of the issues to which purchaser provider managers are required to give highest priority in the forthcoming year. The establishment of a strategy for information system development is included as a medium term requirement.

This means that over the next 18 months, fiveyear strategles, including detailed operational specification for computer systems, will be drawn up for all mental health units. These are likely to entail substantial bids for purchase of equipment, redeployment of administrative staff, and training. High quality bids are likely to succeed.
These central pressures are likely to be supported by the wishes of fundholding GPs for greater clarity about care recelved by their patients, of finance directors for programmes costing details and of purchasers for more numerically based clinical audit.

\section{What is the risk?}

The key danger at this point is that clinicians will fail to participate adequately in the process of designing the systems for their own units. Each mental health service has its own unique circumstances and ways of operating, thus it is not possible to develop a universally satisfactory 'off the shelf system. Detailed customisation is needed for any service. The required input is not in technical detall about programming or software but in defining the operational tasks the computers should undertake. A realistic set of plans needs to be developed for each provider about how each member of the clinical team records their observations of and interventions with each patient, how care review summaries are computerised and how access for all authorised staff is practically arranged. The human-computer interface may be direct (more expenstve on technology and training but probably more accessible and accurate) or mediated through paper. Field trials have shown that the latter approach is far less effective in delivering the major clinical benefits. Interim 'paper in - computer out' approaches (where staff submit major review details on paper but have computer consoles to look up information) may be selected but clinicians are easily put off by being asked to fill in more forms.

If the system is ultimately to support clinical care, cliniclans have to say what they want to know and when and how they need to know it. Modern health service managers are increasingly able but they are not yet psychicl If clinicians do not participate adequately I would predict that the process will still proceed but with four types of flaw.

First, clinical content beyond the minimum data set will be minimal. Useful information, such as drug dosages, patients' preferences, and detail of ongoing relations between statutory and informal carers, none of which would ever be required for central administrative purposes, will be omitted.

Second, systems will be structured around crudely stereotyped notions of the way care is organised. The Care Programme Approach with its cyclical structure of assessment, care plan. key worker and review is inevitably a simplification of the way clinical teams operate. The diverse detail of local operational patterns can only be supplied by the clinicians concerned. 
Third, they will lack flexdbility. Different teams work in different ways, and some clinicians have little or no experience of computerised information systems when they start; inevitably, arrangements which work initially will cease to be satisfactory when individuals in key positions move on or staff become more confident and want greater independence. Systems should be designed to allow adjustment and development of operational arrangements with minimal additional expense and maximum local control.

Fourth, they will convey facts rather than information. People with relatively little understanding of the clinical process and the concerns and strategies of clinicians can design systems which record all observable facts. To make the jump from this to designing systems which convey the clinicians' intent requires a dimension of understanding the full meaning of those facts. This can only be supplied by clinicians.

\section{Why would clinicians not get involved?}

Reasons for not getting involved are numerous: not enough time; do not think the amounts of money concerned should be spent on computers; anxious about confidentiality; innately suspiclous of 'toys'; have not got enough time to learn how to type; what happens to our notes if the computer breaks or gets a virus?

To the extent that these are real issues they can usually be handled. Not necessarlly easily. Each implies tasks. To the extent they constitute the outward face of people's fear that they may have problems with the new technology, or appear ignorant, they are more tricky.

It is essential that in each provider unit some at least one - consultant takes a lead. If there is no one who is already familiar with computerised systems, some clinician needs to get familiar. This is as true for nurses as for doctors.

It is all very well to say that no one has the time or inclination and that everyone's workload is too great. Wherever that happens the losers will be, first the clinictans who will lose out on new technology which could be the central nervous system needed to bring coherence to dispersed care facilities, second the service which will continue to lack the information to argue for more resources, and ultimately - of course - the patients for whom a modern, comprehenstve service will not be available.

So let every service identify lead clinicians now. Your local management may not yet have broached the subject - no matter. Get in first. Make sure that clinical understanding is central in the process. And come on all you, take a leap onto the great cyber super-highway: you will be surprised to learn how enriching and creative it can be. You might even enjoy IT!

\section{References}

DEPARTMENT OF HEALTH (1994) Developing information resources. In Mental Illness Key Area Handbook pp. 145-162. London: HMSO.

INFORMATION MANAGEMENT GROUP (1995) Information to Support Adult (Including Elderty) Mental Health Care. The Need for a New Mental Health Minimum Data Set. Copies avallable from Mrs S. Knight, Room 5 W12. Quarry House. Quarry Hill, Leeds LS2 TUE.

NHS EXXCUTIVE (1995) Priortties and planning guidance for the NHS: 1996/97. EU(95)68.

ROHDE, P. D. \& TAYLOR. J. (1992) Computerised clinical caserecord systems. In Measuring Mental Health Needs (Eds. G. Thornicroft, C. Brewin \& J. K. Wing), pp. 237-257. London: Gaskell.

SECRETARY OF STATE (1992) The Health of the Nation. London: HMSO.

TAYLR. J. (1992) Linking psychiatric registers to decision support systems. Psychiatric Bulletin, 16, 275-278.

G. Glover, Senior Lecturer, Department of Public Health and Primary Care, Charing Cross and Westminster Medical School, London SW10 9NH 